\author{
Military Technical College \\ Kobry El-Kobbah, \\ Cairo, Egypt.
}

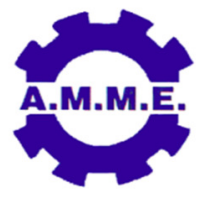

\title{
AN INVESTIGATION INTO THE EFFECT OF CNC-EDM WIRE CUTTING PARAMETERS FOR CROSS-FEED TURNING PROCESS
}

\author{
A. M. Al Wardany ${ }^{*}$, M. A. Mahdy ${ }^{* *}$ and H. A. Sonbol ${ }^{* *}$
}

\begin{abstract}
In this investigation, an experimental study in cylindrical wire EDM machining parameters followed by statistical analysis is presented for cross-feed turning process. At first, the features of rotary spindle are presented. The spindle has been mounted on a conventional four-axis wire EDM machine to provide the workpiece rotation in order to generate free form cylindrical geometries. Several experiments are conducted to investigate the influence of six design factors: the depth of cut $(\mathrm{a})$, gab $(\mathrm{g})$, spindle rotational speed $(\mathrm{n})$, pulse time-on $\left(T_{o n}\right)$, wire feed speed $\left(S_{w}\right)$ and interval time $\left(T_{o f f}\right)$ on the material removal rate (MRR) and surface roughness (Ra) as an indicators of the efficiency and cost-effectiveness of the process. Stainless steel k316 is one of the difficult-to-machine material, was used in this study. An L18 $\left(2^{1} \times 3^{5}\right)$ Taguchi standard orthogonal array is chosen for the design of experiments (DOE) due to the number of factors and their levels in the investigation. Mini tab Software version 16 was used to determine the main effects of the process parameters. Analysis of variance (ANOVA) was performed to find the dependent variables that effect the machining characteristics, Regression analysis is performed to find out the relationship between the different factors and responses, $\mathrm{S} / \mathrm{N}$ ratio analysis is used to establish the optimum condition.
\end{abstract}

\section{KEY WORDS}

WEDM, CWEDM, MRR, Ra, Taguchi's L-18 Orthogonal array.

* Teaching assistant, Department of Production Engineering, Modern Academy, Elmaadi, Cairo, Email: wardany2012@gmail.com and Tel: 01004123154

** Professor, Department of Design and Production Engineering, Ain Shams University, Cairo, Egypt. Introduction 


\section{INTRODUCTION}

EDM is a non-traditional process that is used to remove metal through the action of an electrical discharge of short duration and high current intensity between the tool (electrode) and the workpiece. There are no physical cutting forces between the tool and the workpiece. This process is finding an increasing demand owing to its ability to produce geometrical complex shapes as well as its ability to machine hard materials that are extremely difficult to machine when using conventional process [1].

The concept of cylindrical wire electrical discharge turning (CWEDT) is illustrated in Fig (1). A rotary axis is added to a conventional four-axis wire EDM machine in order to produce cylindrical forms. The electrically charged wire is controlled by the $X$ and $Y$ slides to remove the work-material and generation of the desired cylindrical form.
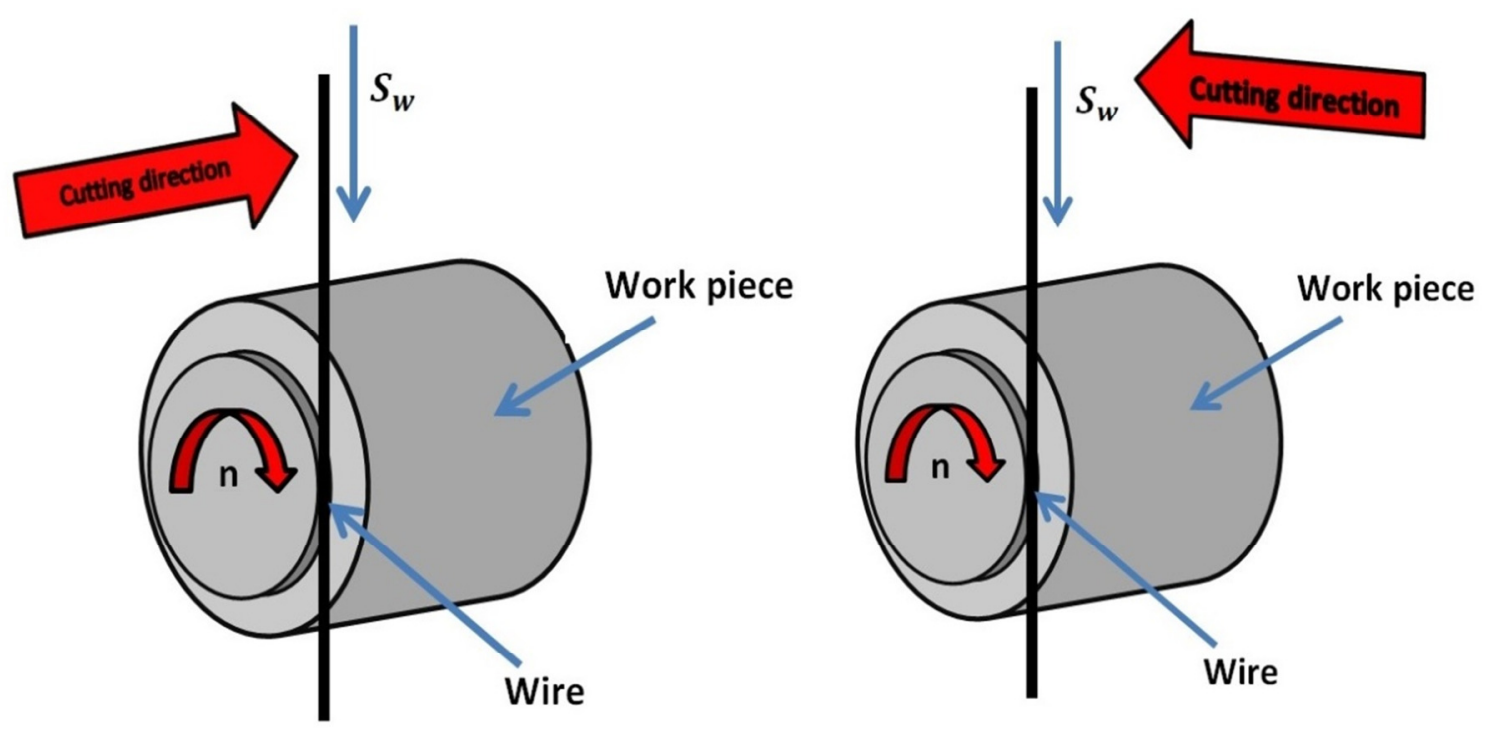

Fig. 1. The concept of turning with wire EDM

The idea of using wire EDM to machine cylindrical parts for manufacturing small pins has been reported by Dr. Masuzawa's research group at University of Tokyo [2-4]. The small- diameter pins can be used as tools for 3D micro-EDM application [6]. Examples of the machined parts using the cylindrical wire EDM method have shown in Refs [2, 4-6].

Qu et al. [5] derived a mathematical model for the material removal rate (MRR) of the CWEDT process. Haddad et al. [7] investigated the longitudinal feed turning by wire electrical discharge machining to evaluate the effects of machining parameters on MRR, surface roughness and roundness by using Taguchi approach. The investigation concluded that only power, voltage and pulse off time has significant effect on MRR and spindle rotational speed has no significant effect on MRR. Also the experiments present power, voltage, pulse off time and spindle rotational speed have significant effect on $\mathrm{Ra}$ and only pulse off time and spindle rotational speed have significant effect on roundness. Power and voltage have more significant effects on $\mathrm{Ra}$ than pulse off time and spindle rotational speed. The effects of pulse off time on 
roundness are more significant than other factors. Aminollah $M$, etal [6], studied the effect of power, time-off, voltage, wire speed, wire tension, and rotational speed on the MRR for longitudinal turning operation. It was concluded that the MRR was significantly increased by the increase of the machining current, the MRR was directly proportional to the gab voltage with significant effect, by the increase of the wire speed the MRR was increased but with no significant effect, by increase of spindle rotation speed and the interval time $\left(T_{\text {off }}\right)$ the MRR was decreased with significant effect, the increase of the wire tension decrease the MRR with less significance effect.

In this investigation, the features of spindle design are presented. Then, statistical analysis methods have been employed to evaluate the effects of machining parameters on material removal rate (MRR), surface roughness $(\mathrm{Ra})$, for cross feed turning process.

The analysis of variance (ANOVA) is widely used to consider effects of factors (input parameters) on responses (output parameters). In experimental investigations, ANOVA is often employed prior to other statistical analyses. Then regression analysis which establishes a relation between independent variables (factors) and dependent variables (responses) is widely applied. A polynomial equation is often derived from regression analysis. To realize the optimal condition, signal- to-noise $(\mathrm{S} / \mathrm{N})$ ratio analysis can be used [8-10].

A good result cannot be gained through statistical analyses of experimental data unless the experimentation is provided with a carefully conducted design of experiments (DOE). Taguchi standard orthogonal arrays are nowadays predominant means of DOE since it has been proved that experiments performed based on orthogonal arrays are more efficient and less costly [11-12].

It can be briefly mentioned that experimentation falls within below steps [6]:

1. Design of experiments (DOE)

2. Conducting experiments

3. Data analysis

In this investigation, these steps are used and the results are reported.

\section{SPINDLE DESIGN FEATURE}

The workpiece rotation is obtained from a spindle submerged in a tank of deionized water. Two jets of high-pressure water are used to flush the workpiece to removes eroded particles from the gap for efficient cutting and maintain a uniform thermoenvironment. This spindle must meet the following design criteria: accuracy, flexibility, high current electrical connection, corrosion Resistance [5]

The picture of the underwater spindle used in this investigation is shown in Fig (2). A DC motor was located above water on the top of the frame. A timing belt was used to transmit the rotational motion to the R30 collet holder. The electric motor gives the rotation motion through an electrical signal received from control board to allow the motor to rotate within range from 30 to $100 \mathrm{rpm}$. 


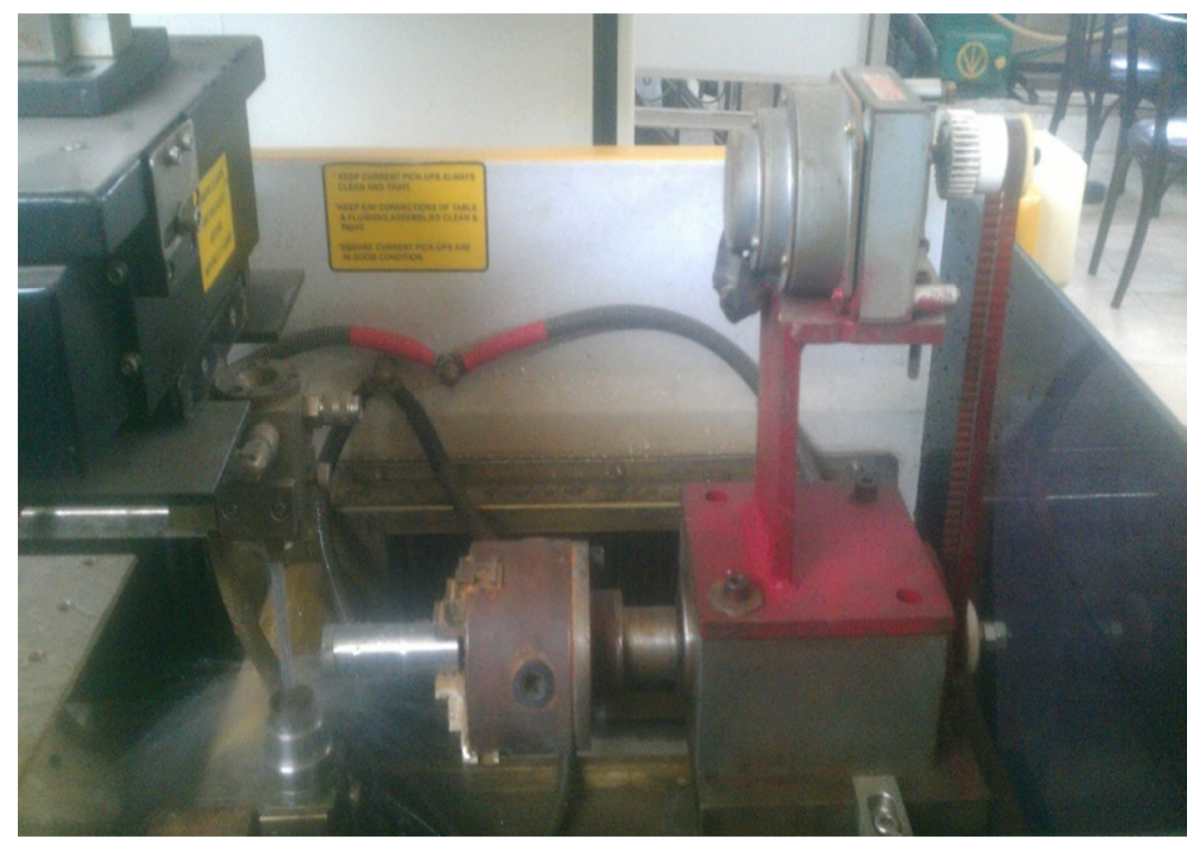

Fig. 2. The underwater spindle in four-axis WEDM machine.

\section{EXPERIMENTAL SETUP}

In this investigation, all experiments are conducted on 4-axis ECOCUT ELPULS -15 wire EDM machine. Several experiments are conducted to investigate the effect of six control factors on the MRR and $\mathrm{Ra}$. The cross-feed turning configuration as shown in Fig (3) is used during this investigation.

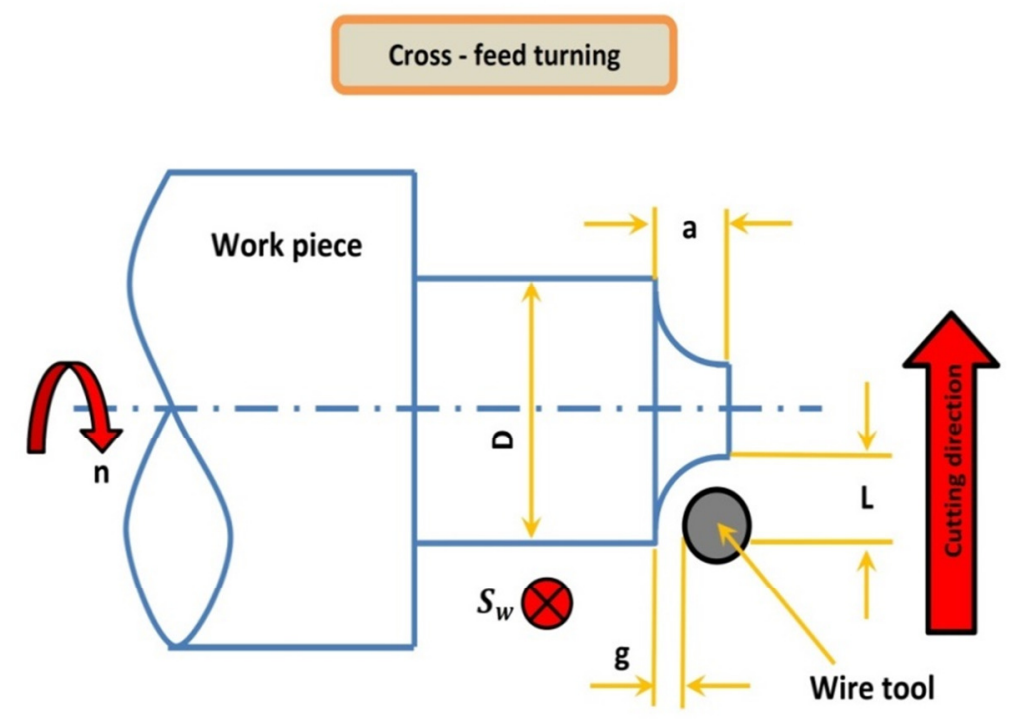

Fig. 3. Principal of cross-feed turning.

Factors and their levels are shown in Table (1). Depth of cut (a), gab (g), spindle rotational speed $(\mathrm{n})$, pulse time-on $\left(T_{o n}\right)$, wire feed speed $\left(S_{w}\right)$ and interval time $\left(T_{o f f}\right)$ 
are adopted as factors (independent variables) which vary during the experiments. Fixed factors are in Table (2). These factors are set apart from the experiment, and they are neither presumed to have effect on the process, nor can vary because of the equipment setup. A proper design of experiments is conducted to perform more accurate, less costly and more efficient experiments. The depth of cut has two levels. Consequently, it has one degree of freedom. Each factor of the other five independent variables has three levels. Consequently, they have 2 degrees of freedom. The total degree of freedom is the summation of each factor degree of freedom. It is obvious that the total degree of freedom here is 11 . When the total degree of freedom is calculated, because of the factors in Table (2) are not variable, they are not included in present analyses.

In this investigation, an L18 $\left(2^{1} \times 3^{5}\right)$ Taguchi standard orthogonal array is selected as the experimental design. The procedure of adoption is to find a standard array which its number of rows is at least one more than the number of degrees of freedom, and its columns are assignable to the factors in the experiments. The first column of this array, a 2-level column, and other columns are filled with the other three level factors involved in this investigation. Each experiment is replicated three times so that, the total number of experiment is 54 . The procedure of selecting an orthogonal array, and assigning factors to columns, explained in details at [8].

After assigning the factors and their levels to the columns, and experimental units, respectively, the experiments should be randomized to assure elimination of human biases. In order to randomize experimental runs a randomization table is employed.

The MRR was measured by dividing the machined volume of the workpiece against the machining time that was achieved. A digital vernier caliper and the optical microscope of the micro hardness tester (Mitutoyo) were used to measure the diameter and the machined length of the workpiece.

The surface roughness ( $\mathrm{Ra}$ ) was measured using a Mitutoyo- surf test 301 . The $\mathrm{Ra}$ values of the surface were obtained by averaging the surface roughness values of 6 $\mathrm{mm}$ measurement length. A cut off length of $10 \mathrm{~mm}$ was used for the surface roughness measurement.

In the pre-experiment or screening experiment the analysis was based on fractional factorial design. However in the actual experiment, Mini tab Software version 16 was used to determine the main effects of the process parameters. Analysis of variant (ANOVA) was performed to find the dependent variables that effect the machining characteristics, Regression analysis is performed to find out the relationship between the different factors and responses, $\mathrm{S} / \mathrm{N}$ ratio analysis is used to establish the optimum condition.

\section{RESULTS AND DISCUSSION}

\section{Analysis of Material Removal Rate (MRR)}

Figure (4) illustrates main factor effects on MRR. It can be seen from Fig (4) that the depth of cut and spindle rotational speed and time off are reciprocally proportional to 
Table 1. Factors, factor levels and factor designation.

\begin{tabular}{|c|l|c|c|c|c|}
\hline \multicolumn{2}{|c|}{ Factor } & \multirow{2}{*}{ units } & \multicolumn{3}{c|}{ Factors levels } \\
\cline { 4 - 6 } & & $\mathbf{1}$ & $\mathbf{2}$ & $\mathbf{3}$ \\
\hline 1 & Depth of cut $(\mathrm{a})$ & $\mathrm{mm}$ & 0.1 & 0.15 & --- \\
\hline 2 & Gab $(\mathrm{g})$ & $\mathrm{mm}$ & 0.03 & 0.05 & 0.06 \\
\hline 3 & $\begin{array}{l}\text { Spindle rotation speed } \\
(\mathrm{n})\end{array}$ & r.p.m & 60 & 70 & 80 \\
\hline 4 & Time on $\left(T_{\text {on }}\right)$ & $\mu \mathrm{s}$ & 5 & 7 & 8 \\
\hline 5 & Wire speed $\left(S_{w}\right)$ & $\mathrm{m} / \mathrm{min}$ & 7 & 8 & 10 \\
\hline 6 & Time off $\left(T_{\text {off }}\right)$ & $\mu \mathrm{s}$ & 4 & 5 & 6 \\
\hline
\end{tabular}

Table 2. Non variable factors used during experiment's.

\begin{tabular}{|c|l|l|}
\hline \multicolumn{2}{|c|}{ Factor } & \multicolumn{1}{c|}{ value } \\
\hline 1 & Wire material & Brass \\
\hline 2 & Wire diameter (mm) & 0.25 \\
\hline 3 & Upper flushing flow rate (liter /min) & 0.6 \\
\hline 4 & Lower flushing flow rate (liter/min) & 0.5 \\
\hline 5 & Workpiece material & Stainless steel k316 \\
\hline 6 & Workpiece hardness (HRB) & 79 \\
\hline 7 & Workpiece diameter (mm) & 25 \\
\hline 8 & Cutting length (mm) & 10 \\
\hline
\end{tabular}

MRR. In addition, the figure also presents that increasing time-on and wire speed causes MRR to increase but not significantly like gab. Time-off, gab have direct significant effect on MRR. But in lower values of gab, the MRR value increases strongly, this because the increase of gab causes increase of voltage and directly proportional to the current. As indicated in Fig (4), the effects of depth of cut and wire speed on MRR are less than the others.

ANOVA is used here to test the null hypothesis with regard to the data gained through experiments. Table (3) is ANOVA Table for MRR. In this study, confidence level was chosen to be $95 \%$. So the P-values which are less than 0.05 indicate that null hypothesis should be rejected and thus the effect of the respective factor is significant. It can be seen from Table (3) that gab $(P=0.00)$ has the most significant impact on MRR. Also, the pulse time-off factor $(P=0.01)$ has moderate significance 


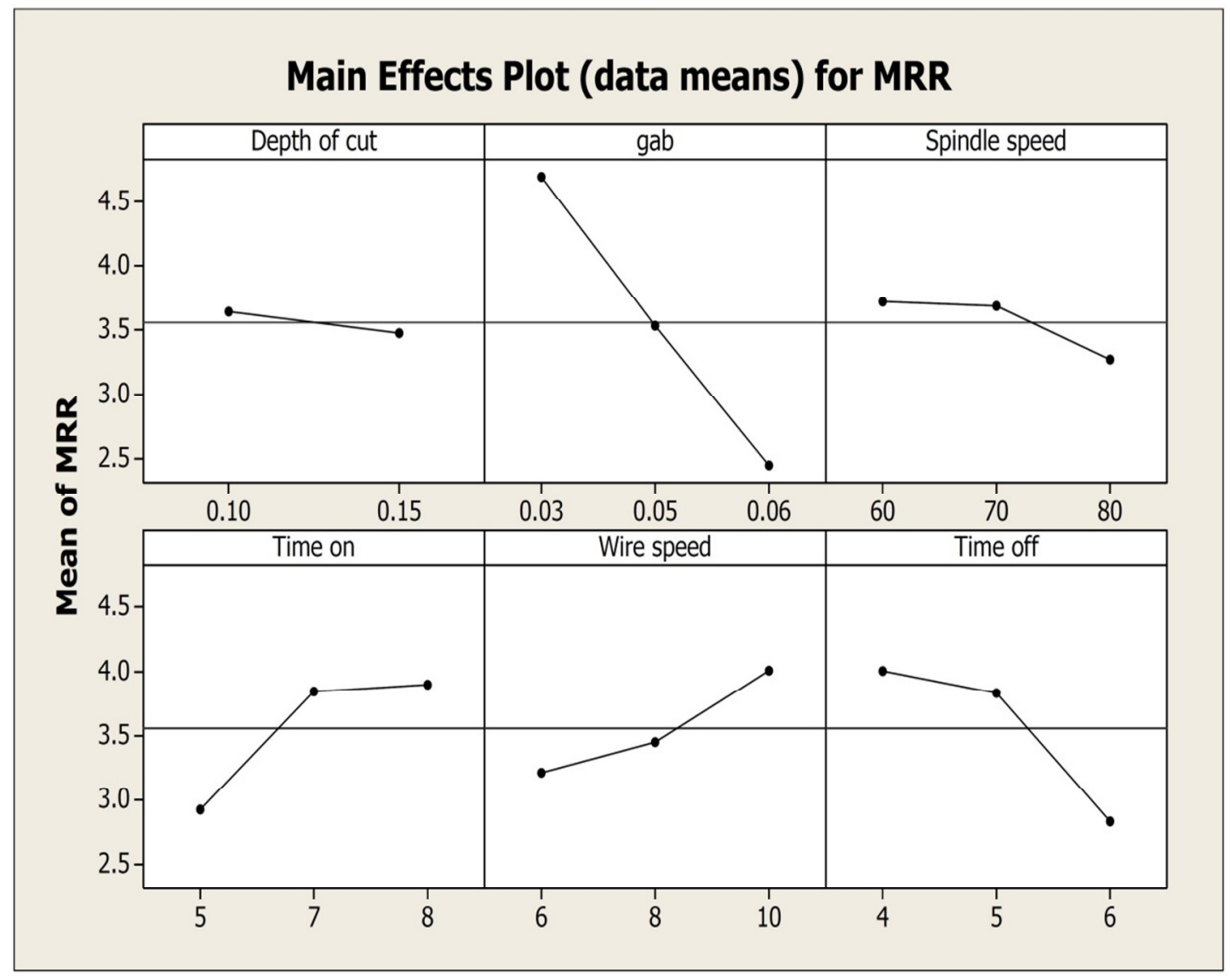

Fig. 4. Plot of the effect of the different parameters on the material removal rate MRR.

effect on MRR. In addition, the effect of pulse Time-on $(P=0.03)$ has less significance to $M R R$, the spindle speed $(P=0.48)$, Depth of cut $(0.62)$ and wire speed $(P=0.14)$ are not significant on MRR as it is indicated in Table (3). In this table, the degree of freedom for total is $n-1$, where $(n)$ is the total number of trials (54). The degree of freedom for the error is the degree of freedom of total minus the degree of freedom for the summation of all factors (53-11).

Regression analysis was performed to find out the relationship between factors and MRR. It is assumed that factors and the response are linearly related to each other, so the regression equation is as follows:

$$
\mathrm{Y}=\beta_{0}+\beta_{1} X_{1}+\ldots \ldots \ldots+\beta_{i} X_{i}+\ldots \ldots+\beta_{n} X_{n}
$$

where $\mathrm{Y}$ is the response and $\beta_{i}$ is the regresses of ith factor and denotes residual.

The derived regression equation is as follows:

MRR = 7.9555 - 3.3092.Depth of cut -72.4417. gab -0.0223. Spindle speed + 0.3445. Time-on + 0.1996. Wire speed - 0.5869. Time-off. 
Table 3. Anova table for material removal rate.

\begin{tabular}{|l|c|c|c|c|c|c|}
\hline \multicolumn{1}{|c|}{ source } & DF & Seq ss & Adj SS & Adj MS & F & P \\
\hline Depth of cut & 1 & 0.370 & 0.370 & 0.370 & 0.24 & 0.624 \\
\hline gab & 2 & 45.393 & 45.393 & 22.696 & 14.95 & 0.000 \\
\hline Spindle speed & 2 & 2.229 & 2.229 & 1.115 & 0.73 & 0.486 \\
\hline Time-on & 2 & 10.823 & 10.823 & 5.412 & 3.56 & 0.037 \\
\hline Wire speed & 2 & 6.042 & 6.042 & 3.021 & 1.99 & 0.149 \\
\hline Time-off & 2 & 14.459 & 14.459 & 7.229 & 4.76 & 0.014 \\
\hline Error & 42 & 63.757 & 63.757 & 1.518 & & \\
\hline Total & 53 & 143.073 & & & & \\
\hline
\end{tabular}

$\mathrm{S} / \mathrm{N}$ ratio is used to detect the optimal condition. The common practice in $\mathrm{S} / \mathrm{N}$ ratio analysis procedure is to calculate the $\eta$ for each treatment combination and to consider the one which presents the largest $\eta$ as the optimal condition. The type of problem which is dealt with here is "the-larger-the-better" static problem [8-9].For such problem is calculated as follows:

$$
\eta=-10 \log _{10}\left(\frac{1}{n} \sum_{i=1}^{n} \frac{1}{y_{i}^{2}}\right)
$$

In which $y_{i}$ is a response value (MRR) and $(n)$ is the number of replications. The rationale behind SNR analysis is to find a setting of parameters in which signals are predominant. This rationale eventually leads to a situation in which the system is least sensitive to noises; it is focused on each factor level rather than treatment combination. Each factor level $\mathrm{S} / \mathrm{N}$ ratio $(\eta)$ is the average of the treatment combinations S/N ratios of the corresponding factor level [13]. Fig (5) and Table (4) illustrates factor level $\mathrm{S} / \mathrm{N}$ ratios ( $\eta$ ). The largest amount of $\eta$ indicates the optimal condition. Optimal factor levels are obtained from Table (4) and are summarized in Table (5).

\section{Analysis of Surface Roughness (Ra)}

Figure (6) illustrates the plot of factor effects on the surface roughness Ra. Figure (6) shows that the gab and the depth of cut factors have the most significant effect on $\mathrm{Ra}$. In addition, wire speed, time-off, spindle speed has direct proportion to the Ra; that is, by increasing gab and depth of cut, Ra decreases significantly. Also Fig. (6) illustrates the effects of time-on ,on Ra is important. As it is indicated, by increasing in the pulse on time values, Ra increases.

In Table (6), the ANOVA Table for Ra is presented. Depth of cut, gab, pulse timeoff, pulse time-on, wire speed and spindle rotational speed are factors which present a $P$-value lower than $\alpha$-level of confidence. It can be seen from Table (6) that gab $(P=0.000)$ and the depth of cut $(P=0.005)$ has the most significant impact on Ra. Also, 


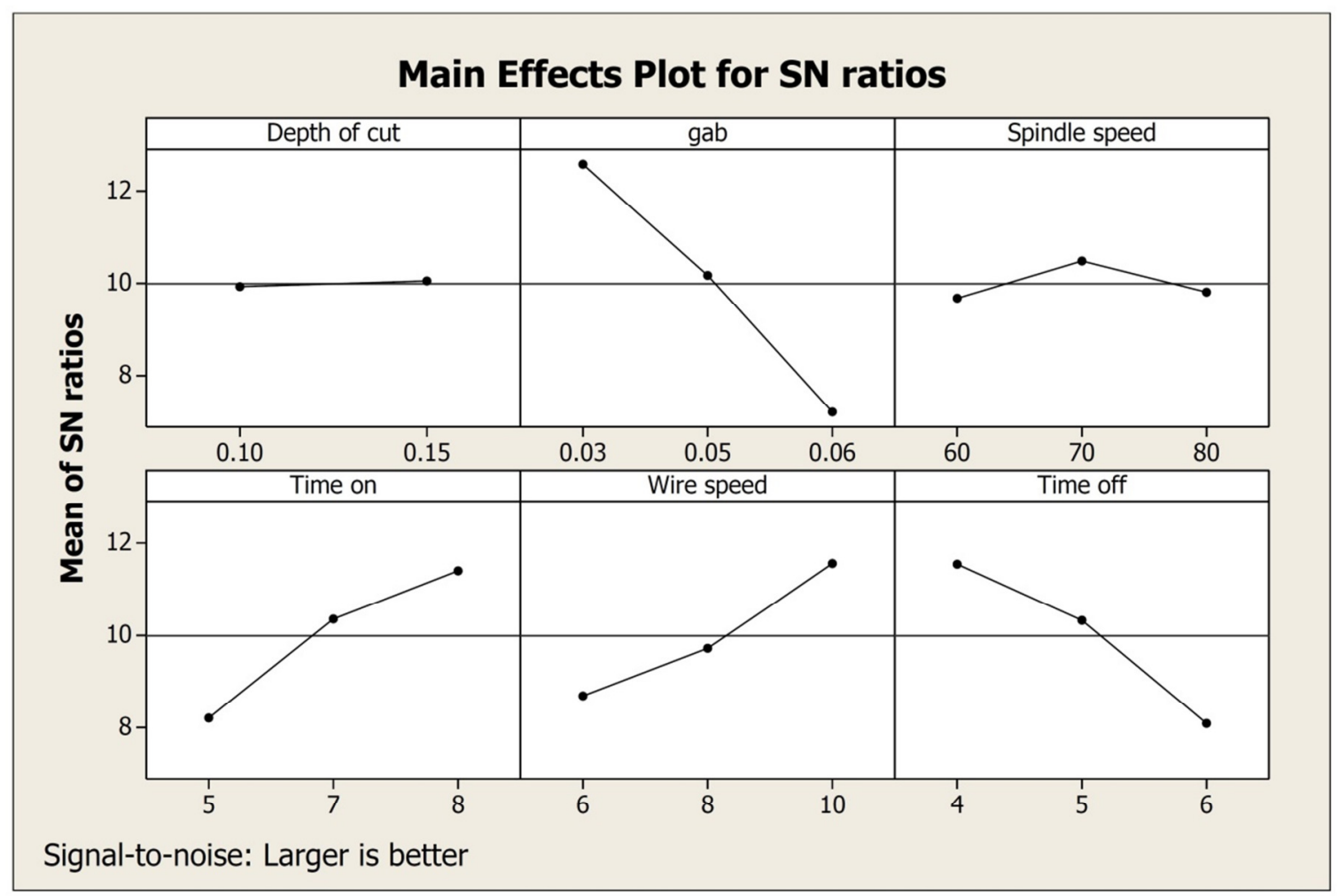

Fia. 5. plot of the $S / N$ ratio for MRR.

Table 4. $\mathrm{S} / \mathrm{N}$ ratios for factor levels for material removal rate.

\begin{tabular}{|c|c|c|c|c|c|c|}
\hline Level & $\begin{array}{c}\text { Depth of } \\
\text { cut }\end{array}$ & gab & $\begin{array}{c}\text { Spindle } \\
\text { speed }\end{array}$ & Time-on & $\begin{array}{c}\text { Wire } \\
\text { speed }\end{array}$ & Time-off \\
\hline $\mathbf{1}$ & 9.926 & 12.579 & 9.675 & 8.208 & 8.686 & 11.544 \\
\hline $\mathbf{2}$ & 10.052 & 10.170 & 10.484 & 10.358 & 9.722 & 10.331 \\
\hline $\mathbf{3}$ & --- & 7.218 & 9.807 & 11.400 & 11.559 & 8.091 \\
\hline Delta & 0.125 & 5.361 & 0.808 & 3.193 & 2.873 & 3.453 \\
\hline Rank & 6 & 1 & 5 & 3 & 4 & 2 \\
\hline
\end{tabular}

Table 5. Optimal factor levels for material removal rate.

\begin{tabular}{|l|c|c|}
\hline \multicolumn{1}{|c|}{ Level } & Optimal level & Optimal amount \\
\hline Depth of cut & 2 & 0.15 \\
\hline Gab & 1 & 3 \\
\hline Spindle speed & 2 & 70 \\
\hline Time-on & 3 & 8 \\
\hline Wire speed & 3 & 10 \\
\hline Time-off & 1 & 4 \\
\hline
\end{tabular}




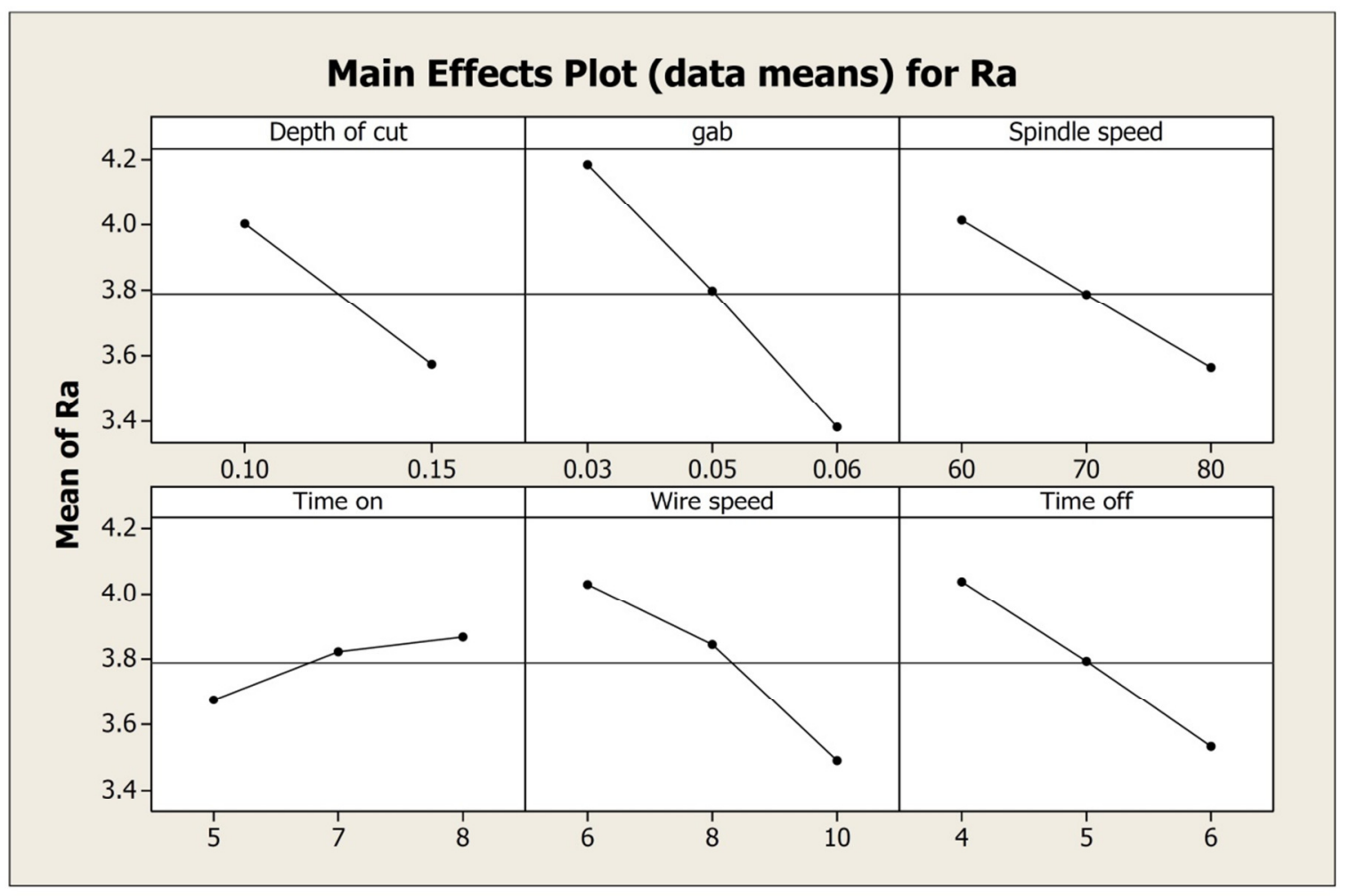

Fig. 6. Plot of the effect of the different parameters on the surface roughness $\mathrm{Ra}$

the wire speed $(P=0.013)$ and pulse time-off factor $(P=0.023)$ has moderate significant effect on $\mathrm{Ra}$. In addition, the spindle rotation speed $(P=0.048)$ have least significant effect on $\mathrm{Ra}$. The effect of pulse Time-on $(P=0.524)$ is not significant on $\mathrm{Ra}$ as it is indicated in Table (6).

Table 6. Anova table for surface roughness

\begin{tabular}{|l|c|c|c|c|c|c|}
\hline \multicolumn{1}{|c|}{ source } & DF & Seq ss & Adj SS & Adj MS & F & P \\
\hline Depth of cut & 1 & 2.4752 & 2.4752 & 2.4752 & 8.89 & 0.005 \\
\hline gab & 2 & 5.7993 & 5.7993 & 2.8996 & 10.42 & 0.000 \\
\hline Spindle speed & 2 & 1.8148 & 1.8148 & 0.9074 & 3.26 & 0.041 \\
\hline Time-on & 2 & 0.3657 & 0.3657 & 0.1828 & 0.66 & 0.524 \\
\hline Wire speed & 2 & 2.7015 & 2.7015 & 1.3508 & 4.85 & 0.013 \\
\hline Time-off & 2 & 2.2912 & 2.2912 & 1.1456 & 4.12 & 0.023 \\
\hline Error & 42 & 11.6898 & 11.6898 & 0.2783 & & \\
\hline Total & 53 & 27.1374 & & & & \\
\hline
\end{tabular}


Equation (4) presents the relationship between factors and $\mathrm{Ra}$ (response) which is the result of response surface linear regression analysis

$\mathrm{Ra}=9.5316$ - 8.5637. Depth of cut - 25.6949.gab - 0.0224.Spindle speed + 0.0656.Time-on - 0.1347.Wire speed - 0.2522.Time-off.

$\mathrm{S} / \mathrm{N}$ ratio is used to detect the optimal condition. The common practice in $\mathrm{S} / \mathrm{N}$ ratio analysis procedure is to calculate the $\eta$ for each treatment combination and to consider the one which presents the largest $\eta$ as the optimal condition. The kind of problem which matches Ra in SNR analysis is "the smaller-the better" static problem [8-9]. For such type of problems signal to noise ratio (SNR) is calculated as follows:

$$
\eta=-10 \log _{10}\left(\frac{1}{n} \sum_{i=1}^{n} y_{i}^{2}\right)
$$

In which: $\eta$ is the signal to noise ratio, $y_{i}$ is the response value (Ra) and $(n)$ is the number of replications. The rationale behind SNR analysis is to find a setting of parameters in which signals are predominant. This rationale eventually leads to a situation in which the system is least sensitive to noises. It is focused on each factor level rather than treatment combination. Each factor level $\mathrm{S} / \mathrm{N}$ ratio $(\eta)$ is the average of the treatment combinations $\mathrm{S} / \mathrm{N}$ ratios of the corresponding factor level. $\eta$ values for $\mathrm{Ra}$ is listed in Table (7) and illustrated in Fig (7). The largest value of $\eta$ indicates the optimal condition [13]. The Optimal settings for Ra are listed in Table (7) and are summarized in Table (8)

Table 7. $\mathrm{S} / \mathrm{N}$ ratios for factor levels for surface roughness.

\begin{tabular}{|c|c|c|c|c|c|c|}
\hline Level & $\begin{array}{c}\text { Depth of } \\
\text { cut }\end{array}$ & gab & $\begin{array}{c}\text { Spindle } \\
\text { speed }\end{array}$ & Time-on & $\begin{array}{c}\text { Wire } \\
\text { speed }\end{array}$ & $\begin{array}{c}\text { Time- } \\
\text { off }\end{array}$ \\
\hline $\mathbf{1}$ & -11.88 & -12.24 & -11.90 & -11.04 & -11.91 & -11.91 \\
\hline $\mathbf{2}$ & -11.02 & -11.57 & -11.44 & -11.58 & -11.65 & -11.49 \\
\hline $\mathbf{3}$ & --- & -10.54 & -11.02 & -11.74 & -10.80 & -10.96 \\
\hline Delta & 0.86 & 1.70 & 0.88 & 0.70 & 1.10 & 0.95 \\
\hline Rank & 5 & 1 & 4 & 6 & 2 & 3 \\
\hline
\end{tabular}




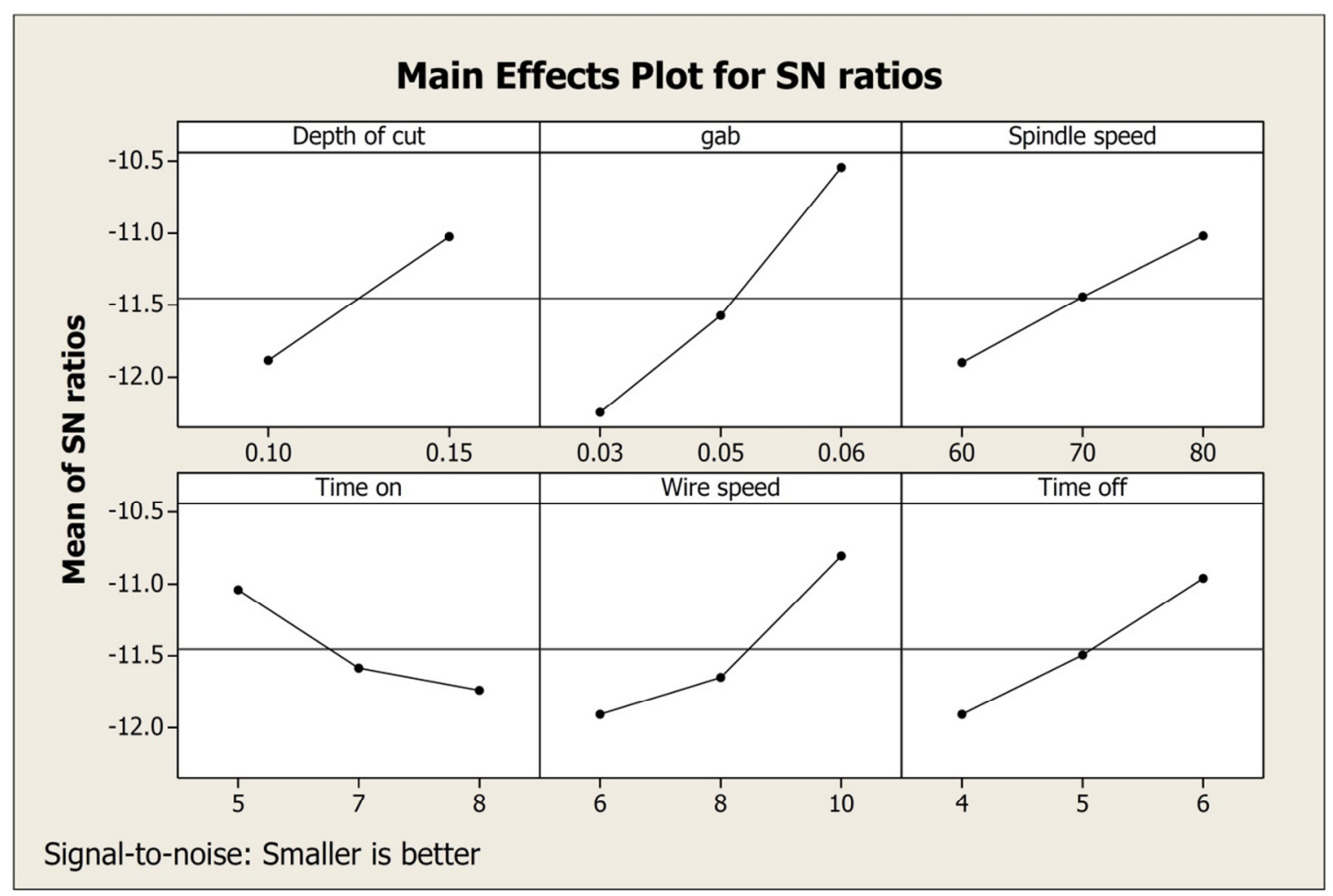

Fig. 7. Plot of the $S / N$ ratio for the surface roughness $R a$.

Table 8. Optimal factor levels for surface roughness.

\begin{tabular}{|l|c|c|}
\hline Level & Optimal level & Optimal amount \\
\hline Depth of cut & 2 & 0.15 \\
\hline gab & 3 & 6 \\
\hline Spindle speed & 3 & 50 \\
\hline Time-on & 1 & 10 \\
\hline Wire speed & 3 & 6 \\
\hline Time-off & 3 & \\
\hline
\end{tabular}




\section{CONCLUSION}

This research has investigated the effect of different cutting parameters on the material removal rate (MRR) and the average surface roughness (Ra) for CNC- Wire EDM turning for cross feed turning process. Based on the experimental results, the main conclusions drawn on machining of stainless steel k316 under various machining parameters are as follows:

Of all the machining parameters investigated the gab $(\mathrm{g})$ was found to be the most significant factor for both the material removal rate MRR and the average surface roughness (Ra). Applying higher values of gab (causes decreasing of the machining current and increases the gab voltage) will lead to high value of the machining responses MRR, Ra. The interval time $\left(T_{o f f}\right)$ was significantly affect the MRR and the average surface roughness (Ra). Applying lower value of $\left(T_{\text {off }}\right)$ will lead to high value of the machining responses MRR, Ra. The pulse duration time-on $\left(T_{o n}\right)$ was significantly affect the MRR. Applying higher value of $\left(T_{o n}\right)$ will lead to high value of the machining responses MRR, Ra. The spindle rotation speed $(n)$ was significantly affect the Ra. Applying higher value of ( $n$ ) will lead to low value of the machining responses MRR, Ra. The depth of cut (a) was significantly affect the Ra. Applying lower value of (a) will lead to high value of the machining responses MRR, Ra. The wire speed $\left(S_{w}\right)$ was significantly affect the Ra. Applying higher value of $\left(S_{w}\right)$ will lead to low value of the machining responses MRR, Ra.

\section{REFERENCES}

[1] S. Sharif, Rival and M.Y. Noordin, "Electrical Discharge Drilling of Titanium Alloy Ti-6246", Proceedings of the National Conference on Advances in Mechanical Engineering (2005) Volume II, May 18-20, Kuala Lumpur: Faculty of Mechanical Engineering, UiTM, 423-430.

[2] Masuzawa, T., Fujino, M., Kobayashi, K., Suzuki, T.," Study on micro-hole drilling by EDM". Bull. Jpn. Soc. Precis. Eng, (1985). 20 (2):117-120.

[3] Masuzawa, T., Kuo, C.-L., Fujino, M, "A combined electrical machining process micronozzel fabrication”. CIRP Ann. (1994), 43,189-192.

[4] Masuzawa, T., Tonshoff, H.K, "Three-dimensional micromachining by machine tools". CIRP Ann , (1997), 46,621-628.

[5] J. Qu, A.J. Shih, R.O. Scattergood, "Development of the cylindrical wire electrical discharge machining process: Part I: Concept, Design and material removal rate", ASME Journal of Manufacturing Science and Engineering, (2002), 124 (3) :702-707.

[6] Aminollah Mohammadi, Alireza Fadaei Tehrani, Ehsan Emanian, Davoud Karimi, "Statistical analysis of wire electrical discharge turning on material removal rate", journal of materials processing technology, (2008), 205: 283289.

[7] M. J. Haddad \& M. Tajik \& A. Fadaei Tehrani \&A. Mohammadi \& M. Hadi," An experimental investigation of cylindrical wire electrical discharge turning process using Taguchi approach", Int J Mater Form , (2009), 2:167179.

[8] Phadke, M.S., "Quality Engineering Using Robust Design" .Prentice-Hall International, Inc., 1989. 
[9] Ross, P.J., "Taguchi Techniques for Quality Engineering”,McGraw Hill, New York, 1988.

[10] Taguchi, G., "Introduction to Quality Engineering", Asian Productivity Organization, Tokyo, 1990.

[11] Hicks, C.R., Turner, K.V,"Fundamental Concepts and the Design of Experiments", Oxford University Press, New York, 1999.

[12] Mohammadi, A., Fadaei, A., Emanian, E., Zarepour, H., Karimi, D., " Statistical analysis of wire electrical discharge turning on material removal rate", journal of materials processing technology , (2008), 205:283-289.

[13] Mori, T, "The New Experimental Design. Taguchi's Approach to Quality Engineering", ASI Company, 1991. 